\title{
Restoring lions Panthera leo to northern KwaZulu-Natal, South Africa: short-term biological and technical success but equivocal long-term conservation
}

\author{
L.T.B. Hunter, K. Pretorius, L.C. Carlisle, M. Rickelton, C. Walker, R. Slotow and J.D. Skinner
}

\begin{abstract}
The success of efforts to re-establish mammalian carnivores within their former range is dependent on three key factors: methodological considerations, the biological requirements of the target species, and the involvement of local human communities for whom large carnivores pose a threat. We consider the role of these factors in the first 13 years of an effort to re-establish wild lions in northern KwaZuluNatal Province, South Africa. We employed soft-release methods to mitigate the characteristic problems associated with restoration of large carnivores. A pre-release captivity period facilitated acclimatization of reintroduced lions and promoted long-term bonding of unfamiliar individuals into cohesive groups. All individuals remained in the release area and established enduring, stable home ranges. Reintroduced lions
\end{abstract}

successfully reproduced and raised $78 \%$ of their cubs to independence. Human activity was the cause of all post-release mortality. Despite rapid population growth and the re-establishment of the species at Phinda Private Game Reserve, the population is small and isolated with little prospect for re-colonizing additional areas where the species has been extirpated, or for connecting with other isolated lion populations in the region. Accordingly, although we essentially overcame the short-term technical and biological challenges facing lion reintroduction, the long-term value of the Phinda population for addressing the conservation issues facing the species remains equivocal.

Keywords KwaZulu-Natal, lion, Panthera leo, Phinda, South Africa, species restoration.

\section{Introduction}

With increasing human population pressures and continued landscape fragmentation the remaining habitat available to wide-ranging mammalian carnivores continues to decline. To compensate, biologists and managers increasingly adopt interventionist approaches to carnivore conservation, among them, species restoration via translocation or reintroduction (IUCN/SSC, 1998). Large carnivores are frequent subjects for restoration projects. Their ecological requirements and potential for conflict with humans mean they are among the first species to disappear from areas affected by human activity. Concomitantly, they often represent a symbol of

L.T.B. Hunter ${ }^{\star}$ (Corresponding author) and J.D. Skinner Mammal Research Institute \& Veterinary Wildlife Unit, University of Pretoria, Private Bag X04, Onderstepoort 0110, South Africa. E-mail Ihunter@wcs.org

K. Pretorius, L.C. Carlisle, M. Rickelton and C. Walker Phinda Private Game Reserve, Private Bag 6001, Hluhluwe 3960, South Africa.

R. Slotow School of Biological and Conservation Sciences, University of KwaZulu-Natal, Howard College Campus, Durban 4041, South Africa.

*Also at: Wildlife Conservation Society, 2300 Southern Boulevard, Bronx, NY 10460, USA.

Received 20 July 2005. Revision requested 8 December 2005. Accepted 20 March 2006. wilderness to the general public. Despite a high profile with the public and the high costs and logistical complexity of such projects, many restoration efforts for large carnivores have received little post-release monitoring and, where monitoring has occurred, success rates of restorations have usually been found to be low (Linnell et al., 1997; Woodroffe \& Ginsberg, 1999; Breitenmoser et al., 2001).

Increasingly, practitioners of restoration realize that socio-political elements are as important for success as biological and technical considerations (Reading \& Clark, 1996; Breitenmoser et al., 2001). This is especially germane in developing countries where human demands for land and resources profoundly limit the opportunities for wildlife restoration. In South Africa dramatic political changes in the last decade have given rise to a reassessment of the social role of game reserves (Wells, 1996). Protected areas are under extreme pressure from the acute economic needs of a poor rural population whose historic access to and benefits from reserves have been extremely limited. Far more than previously in South Africa's history, conservation of wildlife is dependent on the attitudes of people living in proximity to protected areas.

Here, we report on a programme restoring wild lions Panthera leo to a region from which they had been absent 
for many decades. We present the techniques employed and discuss (1) the results relative to post-release behaviour, mortality and reproduction, (2) the longterm management issues facing restoration projects of large carnivores, and (3) the potential for enhancing the conservation outcomes of restoration projects.

\section{Study area}

We evaluated lion restoration at the Phinda Private Game Reserve (hereafter Phinda, described in detail in Balme et al., in press) in the Maputaland region of KwaZulu-Natal Province, South Africa. Prior to Phinda's establishment in 1990 the area comprised a mosaic of private smallholdings farming a mixture of wild game, livestock, and crops such as pineapple and cotton. The prevailing vegetation is woodland dominated by Acacia and Terminalia spp., and previously cultivated areas have given rise to fire-maintained grasslands and wooded grasslands. During 1992-1999 Phinda comprised $176 \mathrm{~km}^{2}$; its current size is $210 \mathrm{~km}^{2}$.

Large carnivores and large herbivores were extirpated in the region before 1990. Resident populations of lions were last recorded in Maputaland in 1938 (Rautenbach et al., 1980; Rowe-Rowe, 1992) and, at the onset of this project, lions occurred in KwaZulu-Natal only in Hluhluwe-Imfolozi Game Reserve (Maddock et al., 1996). Fourteen species of indigenous ungulates, ranging in size from suni Neotragus moschatus to Burchell's zebra Equus burchelli, were present at Phinda's establishment and augmented by supplemental translocations during 1990-1993 (Hunter, 1998b). In addition to lions, cheetahs Acinonyx jubatus were restored during 19921994 in a parallel effort (Hunter, 1998a,b). Except for African wild dogs Lycaon pictus the full guild of indigenous carnivores occurs in the area (Rautenbach et al., 1980).

Phinda is abutted by Zulu communities, commercial livestock farms, and game farms in which landowners are legally permitted to utilize wildlife (Fig. 1). All adjacent communities subsist primarily from wild or domestic ungulates and are generally hostile to large predators. Lions do not occur on private or communal land surrounding Phinda. As prescribed for reserves in South Africa containing lions, the entire perimeter of Phinda $(115 \mathrm{~km})$ is fenced with $1.8 \mathrm{~m}$ high electrified fencing (Plate 1). Three entrance points to the reserve are unfenced and protected by cattle grids and manned gates that are closed at night.

\section{Methods}

Most previous translocations of felids were hardreleases, i.e. in which animals were immediately released at the new site without consideration for acclimation and recovery following capture and transport (Linnell et al., 1997). We adopted soft-release techniques as employed widely in North America, particularly for canids (Moore \& Smith, 1990; Bangs \& Fritts, 1996). Between May 1992 and January 2003 we released 15 lions that had been wild-caught elsewhere in South Africa (Table 1). Thirteen animals from conservancies contiguous with the Kruger National Park (Fig. 1) were released during May 1992-February 1993, the main restoration effort described here. Two males released in 2003 were captured in Pilanesberg National Park and Madikwe Game Reserve (Fig. 1). On arrival at Phinda, each group was held in one of three $80 \mathrm{~m}^{2}$ acclimatization pens. In all groups some animals were unfamiliar with others (Table 1) and therefore we administered a single dose of $100 \mathrm{mg}$ of long-acting perphenazine enanthate (Trilafon, Schering-Plough, Isando, South Africa) to curtail aggressive behaviour (Van Dyk, 1997; Hunter, 1998a). We fitted VHF radiocollars (Telonics, Arizona, USA) to selected females $(\mathrm{n}=6)$ and males $(\mathrm{n}=5)$, representing all prides and coalitions. A single male was implanted with an intra-peritoneal transmitter (Telonics, Arizona, USA) but poor performance precluded their further use (Hunter \& Skinner, 1997).

We conducted three separate releases staggered in time and space (Table 1), for three reasons. Firstly, we hoped that individuals would have had sufficient opportunity to establish home ranges before the potentially disruptive effects of subsequent releases. Secondly, by locating later release sites outside ranges of established individuals, we anticipated that newly released individuals would be less likely to encounter territorial conspecifics soon after release. Thirdly, a decade later, we released two male lions into the population to address the emerging problem of inbreeding; at the time of this release, seven litters totaling 25 cubs had been born to parents that were related. Each group was held for 6-8 weeks and released by opening the enclosure gates, allowing lions to exit of their own accord. We did not provide supplemental feeding after release.

\section{Socio-political considerations}

We began preparing surrounding communities for lion restoration 3 years prior to the first release, with a series of community meetings covering the proposed development of Phinda as a wildlife reserve. Represented at these meetings were the three neighbouring $\mathrm{Zulu}$ communities Mnqobogazi, Nibela, and Mkasa, the Biyala Farmers Association for commercial livestock farmers, individual game farmers, the statutory wildlife 


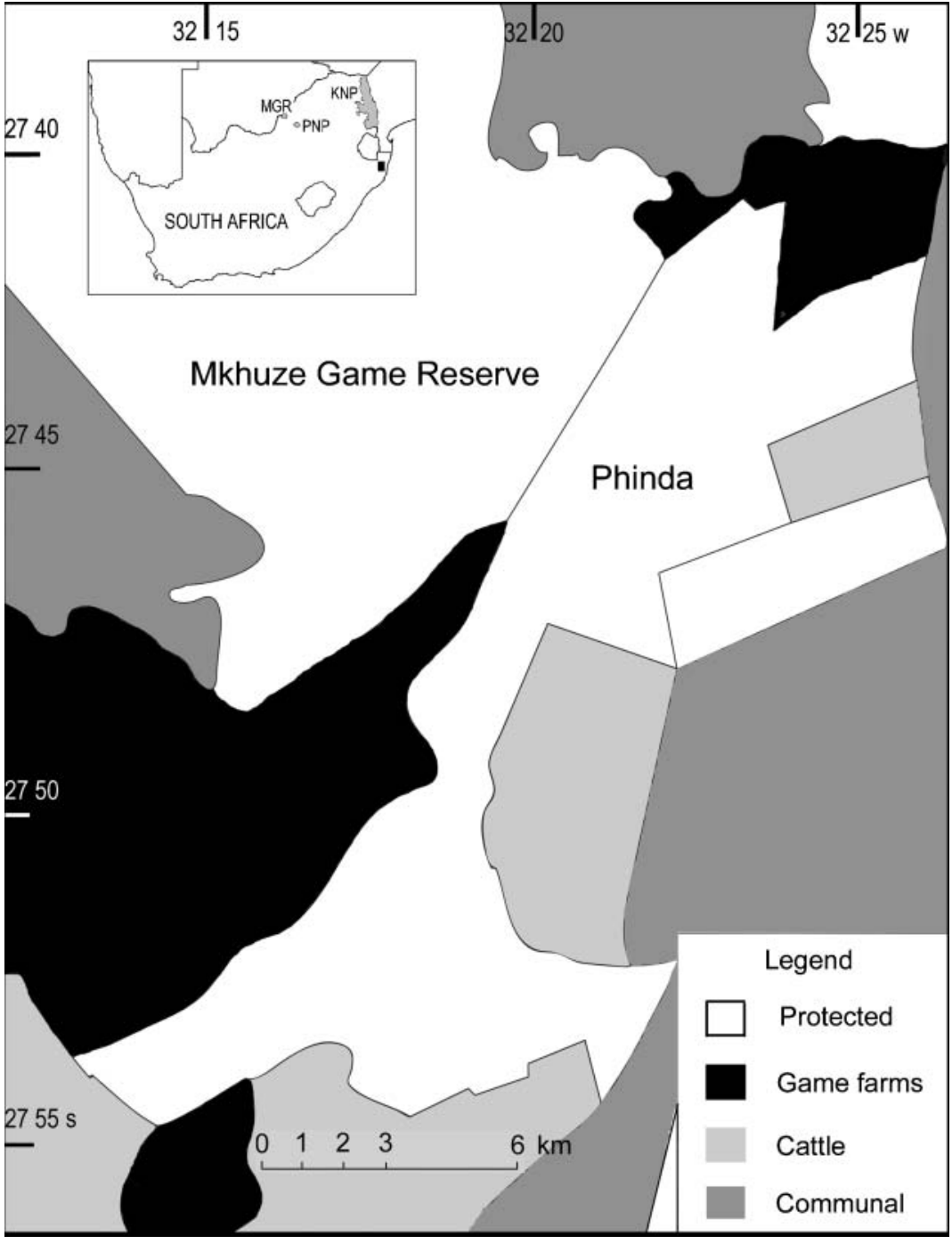

Fig. 1 Phinda Private Game Reserve and surrounding land use types. The boundaries of all protected areas are fenced. Game farms harvest wild, freeranging ungulates commercially. In cattle areas, domestic livestock is the dominant use although these areas also have significant wild ungulate populations, and mixed livestock-game farming is widespread. Human populations on communal land subsist primarily from domestic livestock. The inset shows the location of the main map (small black rectangle). KNP, Kruger National Park complex; MGR, Madikwe Game Reserve; PNP, Pilanesberg National Park. authority Ezemvelo KZN Wildlife Conservation, and the KwaZulu Department of Veterinary Services. Adhering to Ezemvelo KZN Wildlife Conservation's requirements for releasing lions, Phinda management accepted legal responsibility for all released felids and undertook to implement a telemetry-based monitoring programme for 5 years following release. The process culminated in a legally binding document in which all represented communities afforded permission to release lions. Under this agreement, carnivores could not be released without first informing all local communities, and Phinda agreed to annual inspections for the project's first 5 years, in which local authorities visited the reserve to examine boundary fence security and efficacy of monitoring (fence inspections and monitoring of radio-collared felids is conducted daily by reserve personnel).

\section{Results}

\section{Post release behaviour}

Released lions remained in acclimatization pens for up to 24 hours and did not re-enter pens once they had emerged. Lions remained within $1 \mathrm{~km}$ of the pen for up to 1 week, followed by wider movements in which there was weak evidence for homing behaviour in two coalitions of males (Hunter, 1998a). All released lions remained inside Phinda until they died or were translocated; apart from three lionesses that were destroyed 55 days after release (see Mortality section), all animals established enduring ranges for at least 398 days after release (Hunter, 1998a,b).

The captivity period appeared to foster socialization of unfamiliar animals whereby unrelated animals remained together after release (Table 2). The unrelated 


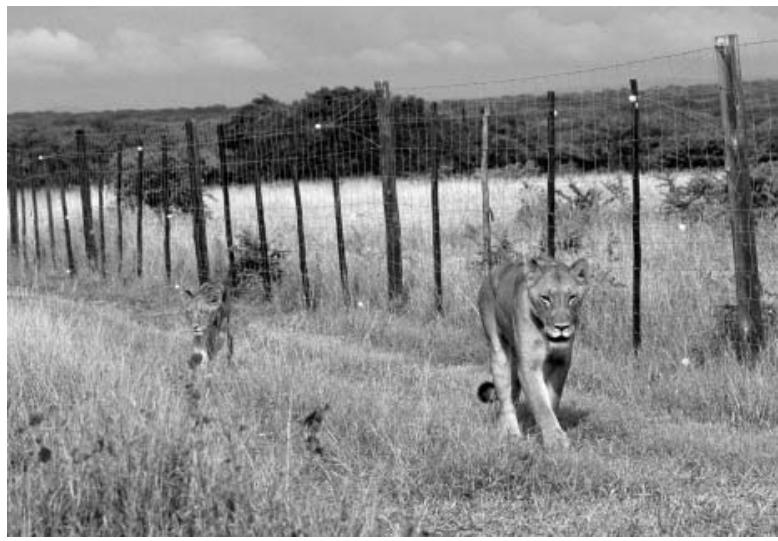

Plate 1 Reintroduced lioness with Phinda-born cub walking next to the electrified boundary fence of Phinda Private Game Reserve. The adjacent property is a mixed cattle and game farm.

lionesses F1 and F2 remained together for 692 days postrelease until the death of $\mathrm{F} 1$. The adult lioness F8 remained with two unrelated sub-adult females F9 and F10 for 55 days until they killed a tourist and were removed. A coalition of male lions comprising two brothers M11 and M12 and one unrelated male M13 remained intact for 516 days, when one of the brothers was killed in a snare. M12 and M13 remained together for a further 80 days until the death of M13. Finally, the unfamiliar half-brothers M88 and M89 (sired by the same male to unrelated females in separate reserves) have remained together for 730 days at the time of writing. There was no significant difference in the index of association between related and unrelated animals that remained together after release (Table 2; females, Mann-Whitney U-test, $z=1.76, \mathrm{P}=0.078$; males, MannWhitney U-test, $z=-1.62, \mathrm{P}=0.105)$.

\section{Mortality}

Except for three lionesses that were destroyed when they killed a person, all founders survived for at least 398 days post-release (Table 2). The mean time that founders survived was $1,212 \pm$ SD 1,344 days $(\mathrm{n}=15)$, including animals subsequently translocated alive. Three founders are still alive at the time of writing, the female F5 more than 13 years after release and the two males M14 and M15 released in January 2003. Four founders were translocated alive from Phinda 1,4553,120 days after their release (Fig. 2, Table 2). Anthropogenic factors accounted for all post-release deaths of founders. During 1993-1994 five adult lions (4 males, 1 female) were killed in cable snares set by poachers. In 1994 three lionesses were destroyed when they killed a tourist. The victim was walking unescorted between her room and the main lodge at night when she apparently encountered three lionesses resting on a pathway. They killed her and were with the body when disturbed by lodge staff. The following morning we darted and destroyed the three lions responsible.

\section{Reproduction and survival}

During 1992-1996 we radio-collared all pregnant lionesses or we knew their daily locations via their association with radio-collared individuals. During 1996-2004 no females were radio-collared but we located all individuals at least twice per week and monitored their reproductive state. Accordingly, apart from unknown litters dying shortly after birth, we are confident that all lion litters born at Phinda were known. Most litters were counted after emergence at approximately 6 weeks. Losses in natal dens are largely

Table 1 Details of the three releases of lions at Phinda Private Game Reserve, arranged chronologically, showing the composition of the groups and the index of association.

\begin{tabular}{|c|c|c|c|}
\hline Release no. (date) & Group composition: unique numbers & Relatedness among group members ${ }^{1}$ & Index of association ${ }^{2}$ \\
\hline \multirow[t]{5}{*}{1 (May 1992) } & 2 adult females: F1, F2 & Both unrelated to all & $F 1: F 2=0.91$ \\
\hline & 218 month old males: M3, M4 & All subadults from same pride & M3:M4 = 0.94 \\
\hline & 318 month old females: F5, F6, F7 & & $\mathrm{F} 5: \mathrm{F} 6=0.89$ \\
\hline & & & $\mathrm{F} 5: \mathrm{F} 7=0.80$ \\
\hline & & & $\mathrm{F} 6: \mathrm{F} 7=0.93$ \\
\hline \multirow[t]{6}{*}{2 (February 1993) } & 1 adult female: F8 & Unrelated to all & $F 8: F 9=1.0$ \\
\hline & & & $F 8: F 10=1.0$ \\
\hline & 212 month old females: F9, F10 & Both unrelated to all & $F 9: F 10=1.0$ \\
\hline & 318 month old males: M11, M12, M13 & 2 brothers, one male unrelated to all & $\mathrm{M} 11: \mathrm{M} 12=0.80$ \\
\hline & & & M11:M13 = 0.73 \\
\hline & & & $M 12: M 13=0.77$ \\
\hline 3 (January 2003) & 2 adult males: M88, M89 & Half brothers (unfamiliar to each other) & M88:M89 = 0.72 \\
\hline
\end{tabular}

${ }^{1}$ No animals from different groups were related.

${ }^{2}$ Index of association is represented as the proportion of all telemetry locations in which same-sex individuals were located together after release. Unrelated pairs are shown in italics (the half-brothers M88 and M89 were born to unrelated females in two separate sites and were not familiar with one another at introduction; they are treated as unrelated). 
Table 2 Fates of individual reintroduced lions at Phinda Private Game Reserve.

\begin{tabular}{llllr}
\hline Release no. (date) & Individual & Source population $^{1}$ & Fate & Days since release $^{2}$ \\
\hline 1 (May 1992) & F1 & KNP & Killed, wire snare & 692 \\
& F2 & KNP & Translocated & 1,455 \\
& M3 & KNP & Killed, wire snare & 398 \\
& M4 & KNP & Killed, wire snare & 596 \\
& F5 & KNP & Alive & 4,580 \\
& F6 & KNP & Translocated & 1,881 \\
& F7 & KNP & Translocated & 3,120 \\
& F8 & KNP & Destroyed & 55 \\
& F9 & KNP & Destroyed & 55 \\
& F10 & KNP & Destroyed & 55 \\
& M11 & KNP & Killed, wire snare & 399 \\
& M12 & KNP & Translocated & 2,908 \\
& M13 & Killed, wire snare & 519 \\
& K85 & Alive & 730 \\
\end{tabular}

${ }^{1}$ KNP, Kruger National Park and contiguous privately-owned conservancies; ENP, Etosha National Park, Namibia (the original source population of the Pilanesberg and Madikwe lions)

${ }^{2}$ At 31 December 2004

unknown and our data therefore represent the minimum numbers of cubs born during the study period.

No founder lionesses were pregnant on release. The first lion cubs were born 12 months after the first release and a total of 95 cubs in 29 litters were born during 1993-2004. Seven cubs died before their sex was determined and the sex of four young cubs is uncertain at the time of writing. Of the remaining 84 cubs, sex ratio was equal. Survivorship of cubs was high relative to recorded survivorship for established populations. Excluding 19 cubs younger than 18 months old translocated from Phinda and 11 cubs still dependent upon mothers at the time of writing, $78.5 \%(n=51)$ of cubs reached 18 months, the minimum age at which young lions can forage independently (Hunter, 1998b). Known causes of cub mortality were mainly natural factors, particularly infanticide by males (Table 3). Nonetheless, human activity played a role; five cubs were killed by infanticidal males in takeovers occurring after the cubs' sires were killed in snares. Similarly, five 4-month old cubs were orphaned when their mother was killed in a snare (the cubs were brought into captivity). Five young cubs disappeared, each from different litters in which siblings survived, suggesting natural causes other than infanticide, given that all cubs in young litters are usually killed in infanticide attacks

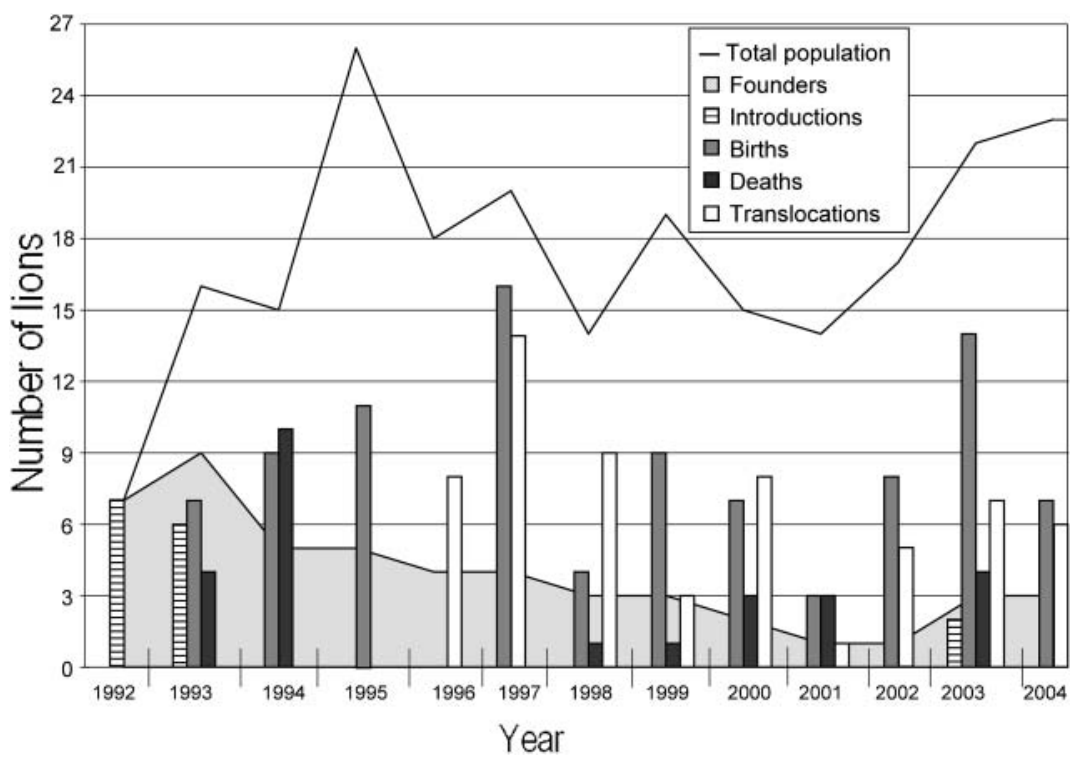

Fig. 2 Population characteristics of the Phinda lions during 1992-2004 showing all gains (births and introductions to Phinda) and losses (deaths and translocations from Phinda). Total population indicates all animals (adults and cubs) alive at the end of each year. The component of the population made up by surviving founders is shown as the shaded area beneath this. 
Table 3 Summary of fates of lions born at Phinda Private Game Reserve during 1993-2004.

\begin{tabular}{|c|c|c|c|c|c|c|}
\hline \multirow[b]{2}{*}{ Age category } & \multirow[b]{2}{*}{ Alive at Phinda* } & \multicolumn{4}{|c|}{ Cause of death } & \multirow[b]{2}{*}{ Removed alive } \\
\hline & & Other lions & Snare & Euthanized & Unknown & \\
\hline$<18$ months & 6 & 8 & & 1 & 5 & 19 \\
\hline$\geqslant 18$ months & 9 & & 4 & & & 38 \\
\hline
\end{tabular}

*At 31 December 2004

(Packer et al., 1988). Although some cubs were born to related parents, we found no evidence of mortality related to inbreeding depression. We euthanized a 4month old cub found with a broken back.

Most animals survived following independence. Four Phinda-born adults were killed in cable snares during 1998-2001, the only post-independence mortalities. A total of 57 (38 post-independence) Phinda-born lions have been translocated to other South African reserves (Fig. 2, Table 3). All other Phinda-born animals are alive at the time of writing $(n=20)$.

\section{Socio-political considerations}

We did not assess the attitudes of surrounding communities empirically and local people had few opportunities to kill lions intentionally because the lions rarely left the reserve. Local people reported lion breakouts 26 times during 1992-1994. Twenty reports were due to misidentification of tracks, usually of spotted hyaenas, leopards or domestic dogs. After 1994 reports of breakouts dropped to 1-2 per year, probably as communities grew accustomed to lion presence in Phinda. Lions left the reserve on six occasions by crossing electrified cattle grids at entry gates or through holes under the fence created by warthogs. On two occasions we discovered breakouts and recovered the individuals, and on one occasion the lions returned to Phinda themselves. On three occasions local people saw lions and alerted us; we recovered the animals the same day. In one case, lions killed ZAR 18,000 worth of wild and domestic stock on one commercial cattle/game farm before being recaptured. This is the only case where lions killed livestock outside Phinda, and the farmer was compensated.

\section{Discussion}

Failure rates of carnivore restoration efforts are often high, leading many authors to conclude that the factors affecting success are not sufficiently understood to justify restoration as a method for conserving large carnivores (Hamilton, 1981; Linnell et al., 1997; Breitenmoser et al., 2001). Our study is the longest to date to monitor translocated African felids post-release and demonstrated that, at least in the short term (13 years), lions can successfully be restored to areas of their former range. The soft-release methods adopted here were novel for large felids and probably increased project success. Unlike most previous attempts to translocate large felids (Van der Meulen, 1977; Hamilton, 1981; Stander, 1990; Ruth et al., 1993), all released animals remained at the release site. In many past efforts hard-released carnivores wandered widely after release, often attempting to return to the capture site (Hamilton, 1981; Stander, 1990; Ruth et al., 1993; Linnell et al., 1997; Woodroffe \& Ginsberg, 1999). The pre-release captivity period probably acclimates animals to changes in their environment and location, fostering acceptance of the new locality (Moore \& Smith, 1990). As a result, soft-released individuals may be more likely to shift geographical fidelity and may be less likely to home (Moore \& Smith, 1990; Hunter, 1998a).

However, although we have no way of experimentally testing the role of the electrified boundary fence in curtailing lion movements, it doubtless contributed substantially to project success. While evidence for homing behaviour in lions was weak (Hunter, 1998a), they would inevitably have dispersed beyond the Reserve's boundary had it not been for the fence. It would be useful to conduct intensive post-release monitoring of translocated lions that underwent the soft release process described here and were also released in areas that are not fenced. However, until such comparisons indicate otherwise, and despite some hesitation in recommending fencing, we believe that temporarily fencing the release sites for carnivore restorations would promote the establishment of a resident population.

Our study demonstrates the propensity of both sexes to form enduring relationships between unrelated individuals housed together before release. This reflects natural behaviour in males, where up to a third of wild coalitions may contain an unrelated member, but it occurs rarely among unrelated females (Packer et al., 2001). In social carnivores a lack of social stability results in increased mortality and movement (Caro \& Collins, 1987; Stander, 1990), which are undesirable characteristics for restoration attempts. However, cohesive family groups or coalitions of lions are rarely available for 
restoration. For example, lions moving from protected areas into farmlands are mostly lone individuals or small groups of dispersers (Anderson, 1981; Stander, 1990). As an alternative to lethal control, capturing such individuals and temporarily maintaining them in captivity may cultivate socialized groups better suited for restoration. Moreover, where the alternative is to release related family groups, it will enhance the genetic heterogeneity of the founder population (Van Dyk, 1997; Druce et al., 2004).

Post-release reproduction and mortality indicated that, unlike other felids (e.g. Eurasian lynx Lynx lynx; Breitenmoser et al., 2001), lions are not difficult to reestablish (see also Hayward et al., 2006). Most lions survived to reproduce and they raised $>75 \%$ of their cubs to independence. Increased cub survival is probably due to low densities of predators and a high density of non-migratory game (Hunter, 1998b). Less than $10 \%$ of cubs died by infanticide, few, if any, were killed by other predators, and no cubs starved. With escalating lion density we would expect increased mortality associated with more territorial conflicts, more pride takeovers, and more subadult animals being forced to disperse into hostile areas as available land within Phinda diminished. However, Phinda's lion population is intensively managed so that the numbers remain fixed at 15-25 animals. Accordingly, while this study illustrates the ability of lions to recolonize small areas rapidly, we cannot draw conclusions about the long-term population dynamics of restored lions left unmanaged.

Causes of lion mortality indicated the restoration process itself had little effect and that human activity after release was the dominant factor. Most deaths of founders were due to snaring that targets ungulates but often kills lions and other carnivores incidentally. Prior to lion reintroduction $>2,000$ mostly old snares were removed from Phinda but it is essentially impossible to account for all. Lions died in old snares set prior to Phinda's establishment $(\mathrm{n}=3$; identified as old snares by the wire being deeply embedded in the anchor tree) as well as in new snares $(n=2)$. Given the reserve's proximity to large, mostly poor communities, some degree of poaching is inevitable and removing freshly laid snares is the primary task of anti-poaching personnel. Phinda's strategies for mitigation include increased numbers of game guards from 10 in 1992 to 34 in 2004, more extensive patrols (the entire perimeter is now patrolled once per day on four-wheel motorbikes to look for signs of illegal entry), and selectively clearing dense vegetation in heavily poached areas, particularly on reserve borders adjacent to local communities.

The importance of community involvement in this effort was inadequately assessed. Nonetheless, had local people been poorly informed about the project, lions moving onto communal or private land would certainly have been killed. Without data specifically assessing the attitudes of local people towards the project it is unclear why they tolerated lions on the few occasions they had the opportunity to kill them. It may have resulted from our outreach efforts but we did not evaluate other activities, particularly community development projects, that may have influenced how communities viewed Phinda (Wells, 1996). Although lion restoration (or the presence of wildlife in general at Phinda) has never expressly been linked with development activities, local people may view them collectively. This uncertainty highlights the need to incorporate rigorous socioeconomic research in restoration projects. Biologists charged with monitoring restoration efforts may segue into community outreach activities without having the training or resources to execute them meaningfully. At worst, this may contribute to project failure (Reading \& Clark, 1997; Breitenmoser et al., 2001) or, as here, it may obscure the reasons for success. Well planned interdisciplinary efforts to address this deficiency in carnivore restoration efforts (Davies \& du Toit, 2004) should form the model for future projects.

Large lion populations are now rare outside protected areas and the species is regionally endangered in West Africa (Bauer \& Van Der Merwe, 2004). Restoration of lions should not be viewed as a panacea to the threats facing the species, and protection of extant populations is clearly the higher priority at the continental scale. Nonetheless, the methods reported here hold promise for conserving lions in some regions. We have demonstrated that lions are unproblematic to translocate and that re-established populations can endure for at least 13 years post-release. Since 1992, lions have been restored to at least 4,560 $\mathrm{km}^{2}$ in 21 South African sites (Hunter et al., 2004). These methods are being adopted in other areas undergoing land-use changes as in southern Africa, for example in Namibia (Stander, 2003), and could conceivably find application to regions recovering from civil war, for example certain protected areas in Angola, Mozambique, Rwanda and Uganda where lions are extinct or relict. Similarly, lion populations closed to dispersal and immigration because of anthropogenic barriers may benefit from an infusion of new genetic material via supplementary translocations. The Ngorongoro Crater population is one well studied candidate area (Packer et al., 1991) but there are numerous isolated and small populations in Africa that could warrant the same intervention. Finally, the lessons learned here could be applied to reintroducing the Asiatic lion to areas of its former range. An attempt, in 1957, to establish a second population in Chandrprabha Sanctuary, Uttar Pradesh (the only free-ranging Asiatic 
lion population is in the Gir forests, Gujarat) failed because of a lack of monitoring, the small size of the new sanctuary, and because lions moved outside the sanctuary, leading to conflicts with people and poisoning and poaching of the lions (Negi, 1965). This translocation did not use the methods described here. Preparations are underway to restore lions to the Kuno Wildlife Sanctuary in Madhya Pradesh in 2008 (Johnsingh et al., 2007) that could benefit from the South African experience.

Restoration projects of lions in South Africa will fail to make a meaningful contribution to species conservation unless the long-term challenges facing them are addressed. Lions in confined or small populations can lose genetic variability because of reduced gene flow, genetic drift, inbreeding and environmental stochasticity (Bjorkland, 2003; Dubach et al., 2005). In extreme cases this may lead to population decline or demographic problems, as exemplified by the lions in Hluhluwe-Imfolozi Game Reserve (Maddock et al., 1996). Notwithstanding our success in bonding unrelated individuals, lions in Phinda are descended from few founders, the population is closed, and inbreeding has occurred since 2000, already requiring one release of new founders. Even with this introduction there are still only two unrelated male lineages at Phinda and future inbreeding is inevitable unless further supplementary translocations are performed regularly. Ironically, wildlife managers have to tackle the more immediate problem of rapid population growth. At Phinda, and at all South African sites with restored lions, the species is maintained in low densities to limit the impact of predation on enclosed ungulate populations while also satisfying tourism demands (Hunter, 1998b; Hunter et al., 2004). More than half of cubs born in Phinda have been translocated elsewhere and contraception of some adults was initiated in 2004.

Whether restoration of large carnivores succeeds in the long-term depends largely on the space available to them. Negotiations are underway between all regional stakeholders to consolidate $500 \mathrm{~km}^{2}$ of government and privately-owned land into a single conservation area. A proposed second phase would combine $c .3,000 \mathrm{~km}^{2}$ into one contiguous tract incorporating corridors connecting isolated populations of lions and other large mammals. Although laudable, the obstacles facing the plan are formidable. Inter alia, incompatible expectations on the ownership, utilization and management of wildlife have resulted in slow progress. This dialogue has been ongoing since before lions were released at Phinda, and the reserve remains fenced off from its neighbours. Currently, there is no opportunity for the Phinda population naturally to recolonize areas in the region where lions have been extirpated. Similarly, even though the nearest population of lions (in HluhluweImfolozi Game Reserve) is only $15 \mathrm{~km}$ away, the two populations are separated by electrified fences, a major national highway and human-dominated land uses that do not tolerate large carnivores. Connecting the two populations would have benefits for both, especially in reducing the potential problems of inbreeding, but has never been seriously considered in light of the physical and socioeconomic obstacles. Assuming the status quo is maintained, the re-established lion population at Phinda will invariably remain a small, isolated outlier with limited value to the conservation of the species at a larger regional, national or continental scale.

\section{Acknowledgements}

We thank the directors and staff of Phinda, the Schuette family of Bumbeni Game Ranch, the Mnqobogazi, Nibela and Mkasa Tribal Authorities, and the Biyala Farmer's Association for their support. Sean Carlisle, Martin Haupt, Neil Mostert, Karl Rosenberg, Jeremiah Skosana and Gus van Dyk provided invaluable field assistance in monitoring and Dave Cooper performed post-mortem examinations of animals. This research was funded by CC Africa, the IUCN Cat Specialist Group, a Pittsburgh Zoo Conservation Fund Award, a University of Pretoria Research Assistantship (to LTBH) and grants from the Foundation for Research Development and W.H. Craib Memorial Trust (to JDS). An earlier version of this paper was improved by comments from Gay Bradshaw, Craig Packer and two anonymous referees.

\section{References}

Anderson, J.L. (1981) The re-establishment and management of lion Panthera leo population in Zululand, South Africa. Biological Conservation, 1, 107-117.

Balme, G., Slotow, R. \& Hunter, L.T.B. (in press) Feeding habitat selection by hunting leopards Panthera pardus in a woodland savanna: prey catchability versus abundance. Animal Behaviour.

Bangs, E.E. \& Fritts, S.H. (1996) Reintroducing the gray wolf to central Idaho and Yellowstone National Park. Wildlife Society Bulletin, 24, 402-413.

Bauer, H. \& Van Der Merwe, S. (2004) Inventory of free-ranging lions Panthera leo in Africa. Oryx, 38, 26-31.

Bjorkland, M. (2003) The risk of inbreeding due to habitat loss in the lion (Panthera leo). Conservation Genetics, 4, 515-523.

Breitenmoser, U., Breitenmoser-Wursten, C., Carbyn, L.N. \& Funk, S.M. (2001) Assessment of carnivore reintroductions. In Carnivore Conservation (eds J.L. Gittleman, S.M. Funk, D.

Macdonald \& R.K. Wayne), pp. 241-281. Cambridge University Press, Cambridge, UK.

Caro, T.M. \& Collins, D.A. (1987) Male cheetah social organisation and territoriality. Ethology, 74, 52-64. 
Davies, H.T. \& du Toit, J. (2004) Anthropogenic factors affecting wild dog Lycaon pictus reintroductions: a case study in Zimbabwe. Oryx, 38, 32-39.

Druce, D., Genis, H., Braak, J., Greatwood, S., Delsink, A., Kettles, R., Hunter, L. \& Slotow, R. (2004) Population demography and spatial ecology of a reintroduced lion population in the Greater Makalali Conservancy, South Africa. Koedoe, 47, 103-118.

Dubach, J., Patterson, B.D., Briggs, M.B., Venzke, K., Flamand, J., Stander, P., Scheepers, L. \& Kays, R.W. (2005) Molecular genetic variation across the southern and eastern geographic ranges of the African lion Panthera leo. Conservation Genetics, 6, 15-24.

Hamilton, P.H. (1981) The Leopard (Panthera pardus) and the Cheetah (Acinonyx jubatus) in Kenya: Ecology, Status, Conservation and Management. Unpublished report for US Fish \& Wildlife Service, African Wildlife Leadership Foundation and Government of Kenya, Nairobi, Kenya.

Hayward, M.H., Adendorff, J., O'Brien, J., Sholto-Douglas, A., Bissett, C., Moolman, L.C., Bean, P., Fogarty, A., Howarth, D., Slater, R. \& Kerley, G.I.H. (2006) The reintroduction of large carnivores to the Eastern Cape, South Africa: an assessment. Oryx, 41, 205-214.

Hunter, L.T.B. (1998a) Early post-release movements and behaviour of reintroduced lions and cheetahs, and technical considerations in large carnivore restoration. In Proceedings of a Symposium on Cheetahs as Game Ranch Animals (ed. B.L. Penzhorn), pp. 72-82. S.A. Veterinary Association, Onderstepoort, South Africa.

Hunter, L.T.B. (1998b) The behavioural ecology of reintroduced lions and cheetahs in the Phinda Resource Reserve, northern KwaZuluNatal, South Africa. PhD thesis, University of Pretoria, Pretoria, South Africa.

Hunter, L.T.B. \& Skinner, J.D. (1997) Effect of habitat type on performance of intraperitoneal and external radiotransmitters in lions. Journal of Wildlife Research, 2, 213-216.

Hunter, L., Slotow, R., Van Dyk, G. \& Varian-McCallum, S. (2004) Reintroducing the African lion Panthera leo in South Africa: short-term success but is it conservation? In Carnivores 2004: Expanding Partnerships in Carnivore Conservation (ed. A. Delach), pp. 175. Defenders of Wildlife, Washington, DC, USA.

IUCN/SSC (1998) IUCN Guidelines for Reintroduction. IUCN, Gland, Switzerland \& Cambridge, UK.

Johnsingh, A.J.T., Goyal, S.P. \& Qureshi, Qamar (2007) Preparations for the reintroduction of Asiatic lion Panthera leo persica into Kuno Wildlife Sanctuary, Madhya Pradesh, India. Oryx, 41, 93-96.

Linnell, J.D.C., Odden, J., Smith, M.E., Aanes, R. \& Swenson, J. (1997) Translocation of carnivores as a method for problem animal management: a review. Biodiversity \& Conservation, 6, 1245-1257.

Maddock, A., Anderson, A., Carlisle, F., Galli, N., James, A., Verster, A. \& Whitfield, W. (1996) Changes in lion numbers in Hluhluwe-Umfolozi Park. Lammergeyer, 44, 6-18.

Moore, D.E. \& Smith, R. (1990) The red wolf as a model for carnivore reintroductions. Symposium of the Zoological Society of London, 65, 263-278.

Negi, S.S. (1965) Transplanting of Indian lion in Uttar Pradesh state. Cheetal, 12, 98-101.

Packer, C.P., Herbst, L., Pusey, A.E., Bygott, D.J., Hanby, J.P., Cairns, S.J. \& Borgerhof Mulder, M. (1988) Reproductive success of lions. In Reproductive Success: Studies of Individual
Variation in Contrasting Breeding Systems (ed. T.H. CluttonBrock), pp. 363-383. University of Chicago Press, Chicago, USA.

Packer, C., Pusey, A.E. \& Eberly, L.E. (2001) Egalitarianism in female African lions. Science, 293, 690-693.

Packer, C., Pusey, A.E., Rowley, H., Gilbert, D.A., Martenson, J \& O'Brien, S.J. (1991) Case-study of a population bottleneck lions of the Ngorongoro Crater. Conservation Biology, 5, 219-230.

Rautenbach, I.L., Skinner, J.D. \& Nel, J.A.J. (1980) The past and present status of mammals of Maputaland. In The Ecology of Maputaland (eds M.N. Bruton \& K.H. Cooper), pp. 322-345. Rhodes University, Grahamstown, South Africa.

Reading, R.P. \& Clark, T.W. (1996) Carnivore reintroductions: an interdisciplinary examination. In Carnivore Behavior, Ecology and Evolution, Volume II (ed. J.L. Gittleman), pp. 296-336. Cornell University Press, New York, USA

Rowe-Rowe, D.T. (1992) The Carnivores of Natal. Natal Parks Board, Pietermaritzburg, South Africa.

Ruth, T.K., Logan, K.A., Sweanor, L.L., Smith, J.F. \& Temple, L.J. (1993) Evaluating Mountain Lion Translocation. Final Report.. Unpublished Report, Hornocker Research Institute, Moscow, Idaho, USA.

Stander, P.E. (1990) A suggested management strategy for stock-raiding lions in Namibia. South African Journal of Wildlife Research, 20, 37-43.

Stander, P.E. (2003) The Ecology of Lions and Cheetahs Reintroduced to the Kalahari Game Lodge, Namibia. PCT Research Paper No.2, Predator Conservation Trust, Windhoek, Namibia.

Van der Meulen, J.H. (1977) Notes on the capture and translocation of stock-raiding lions in north eastern and north western Rhodesia. South African Journal of Wildlife Research, 7, 15-17.

Van Dyk, G. (1997) Reintroduction techniques for lion (Panthera leo). In Proceedings of a Symposium on Lions and Leopards as Game Ranch Animals (ed. J. van Heerden), pp. 82-91. Wildlife Group of the South African Veterinary Association, Onderstepoort, South Africa.

Wells, M.P. (1996) The social role of protected areas in the new South Africa. Environmental Conservation, 23, 322-331.

Woodroffe, R. \& Ginsberg, J.R. (1999) Conserving the Africa wild dog Lycaon pictus. II. Is there a role for reintroduction? Oryx, 33, 143-151.

\section{Biographical sketches}

Luke Hunter led the research on reintroduced felids at Phinda, and now heads the Great Cats Program of the Wildlife Conservation Society, New York.

Kevin Pretorius, Les Carlisle, Martin Rickelton and Carl Walker worked for Conservation Corporation (CC) Africa during the time of the study as the team responsible for wildlife and reserve management at Phinda.

Rob Slotow leads a programme at the University of KwaZulu-Natal integrating work on restored lion populations across South Africa, including the lions at Phinda.

John Skinner is Professor Extraordinaire in the Veterinary Wildlife Unit at the University of Pretoria and oversaw the first 5 years of the project. 